\title{
Discretion Drift in Primary Care Commissioning in England: Towards a Conceptualisation of Hybrid Accountability Obligations
}

Oz Gore - z.gore@ leicester.ac.uk

University of Leicester School of Business

INTO

Leicester

United Kingdom

Imelda McDermott

University of Manchester

Division of Population Health, Health Services Research \& Primary Care

Manchester

United Kingdom

Katherine Checkland

University of Manchester

5th floor, Williamson Building

Oxford Road

:manchester

manchester

United Kingdom

M13 9PL

Pauline Allen

London School of Hygiene and Tropical Medicine

Public Health and Policy

London

United Kingdom

Valerie Moran

London School of Hygiene and Tropical Medicine

Department of Health Services Research and Policy

London

London

United Kingdom

(1)

\section{Abstract}

In the context of welfare delivery, hybrid organisations mix public and 'new' market, social, and professional types of mechanisms and rationales. This paper contributes to our understanding of accountability within hybrid organisations by highlighting how accountability obligations can become hybrid, simultaneously formal and informal. Instead of seeing accountability as hybrid only in the sense of the co-existence of types of organisational mechanisms and structures (i.e., the prevalence of both state and market types), we examine accountability arrangements governing a hybrid model - primary care commissioning in England - and interrogate the relationships between accountability actors and their accountability forums. We conceptualise 'hybrid accountability obligations' as a state whereby the nature of obligation underpinning accountability relationships is

This article has been accepted for publication and undergone full peer review but has not been through the copyediting, typesetting, pagination and proofreading process, which may lead to differences between this version and the Version of Record. Please cite this article as doi: $10.1111 / \mathrm{padm} .12554$ 
both formal-informal and vertical-horizontal concurrently. The paper concludes by highlighting the consequences of this kind of hybridity accountability, namely how it extended discretion from welfare delivery to the domain of welfare governance.

\section{Funding Information}

This report is based on independent research commissioned and funded by the NIHR Policy Research Programme via the Policy Research Unit in Commissioning and the Healthcare System. The views expressed in the publication are those of the author(s) and not necessarily those of the NHS, the NIHR, the Department of Health, 'arms' length bodies or other government departments.

\section{Acknowledgement}

We are grateful to our participants who were very generous in allowing us access to their organisations at a time of considerable turmoil and change.

)

\section{1 | INTRODUCTION}

The introduction of partnership working, policy networks, service delivery outsourcing, quasi-market competitive tendering, and agencification led to layering (Streeck and Thelen 2005) or sedimentation (Olsen 2009) in public organisations as "old and new institutions co-exist and co-evolve even if they are founded on partly inconsistent principles" (Christensen \& Lægreid, 2011, p. 419). In this context, the notions of 'hybrid' and 'hybridity' gained traction as conceptualisations of recent developments in welfare delivery (Denis, Ferlie, and Van Gestel 2015; Mair, Mayer, and Lutz 2015; Polzer et al. 2016). Nonetheless, scholars argue that research has over focused on debating how paradigms co-exist, overturn, replace, or complement each other in hybrid organisations. Additional ways of engaging with hybridity are needed as the analytical category of hybridity has been applied inconsistently across studies, with some claiming that it lacks conceptual clarity (Mair, Mayer, and Lutz 2015; Polzer et al. 2016).

I This paper contributes to an understanding of accountability in hybrid public organisations by exploring and conceptualising what policy reforms rooted in hybrid logics and intents might do to accountability relations per se and whether (and in what way) these becomes hybrid in themselves. To begin a conversation about the possibility of seeing accountability itself as hybrid rather than studying accountability within organisational models which are deemed hybrid, we examine the ambiguities resulting from an accountability mechanism put in place in the recent, radical overhaul of the National Health Service (NHS) in England, following the election of a Coalition Government in 2010. Under the Health and Social Care Act (HSCA) 2012, Clinical Commissioning Groups (CCGs) - new membership-based, locally-oriented healthcare commissioning organisations - gained responsibility for commissioning (or purchasing) health care services for their registered population. The HSCA reinforced the place of semi-autonomous agencies in welfare delivery (Overman and Thiel 2016), attempted hybridisation of managers and clinicians in healthcare (Mcgivern et al. 2015), and brought conflicts of interest to the fore (Boyce and Davids 2009). This organisational change is thus of interest as it shares common characteristics with a range of public sector modifications currently affecting Western countries (Turner, LourenÇo, and Allen 2016).

Instead of cataloguing the type of accountability mechanism or commenting on the type of organisational response (e.g., whether it is 'market' or 'state' based or whether it is private or public), we focus on accountability relationships (Bovens 2007) and highlight how the nature of obligation between actors and their forums became a source of uncertainty. We contend that within hybrid public organisations, accountability obligations might be modified not only in terms of the co-existence of state and market organisational principles (e.g., using 
competitive-tendering as an accountability mechanism for public allocation), but also in ways which turn the relationships between accountability forums and actors into an ambiguous, almost inoperable requirement. We find that hybrid public organisations might affect accountability obligations by informalising formal obligations and formalising informal obligations. Furthermore, we observe how, in the case of CCG governance and regulation, hybrid accountability obligations led to higher levels of practitioner manoeuvrability and to an extension of healthcare managers' discretion and agency from the domain of healthcare delivery to healthcare governance. As managers developed what they called 'workarounds', their actions extended from the domains of their designated practice (the management of healthcare service delivery) into foundational domains of public administration such as decisions on what constitutes public and private affairs, what should or should not be regarded as a conflict of interest, and how professionals participate in decision-making around public resource allocation. The paper, then, contributes by suggesting and demonstrating that efforts to 'liberate' local organisations from the perceived burden of bureaucratic accountability with a view to ensuring professional input into commissioning decisions has resulted in governance arrangements that are uncertain, allowing discretion in areas beyond the clinical, with unintended consequences for transparency, accountability and democratic oversight.

\section{2 | HYBRID PUBLIC ORGANISATIONS AND PRACTITIONER ACCOUNTABILITY}

Changes towards hybridity were shown to diminish the centrality of public accountability (Behn 1998; Newberry 2015) and within hybrid public organisation models accountability now carries a polyphony of definitions (Bovens 2007). It is multidimensional (Christensen and Lægreid 2011) and places not always commensurable demands on both public practitioners and organisations (Radin 2010), thus leading to challenges to how public bodies are held to account, to whom they are accountable, and to the character and scope of accountability relationships. The problems of policy implementation are not new (Van Meter and Van Horn 1975), but as the shift from government to governance enacts decentralisation and distribution of functions and responsibilities, the complexity of policy implementation increases (Agranoff 2007). On the backdrop of managerial reforms, a view that "bureaucratic discretion is the nemesis of accountability" (Brodkin 2008, p. 317) is prevalent and accountability mechanisms are often advanced as guarantors of better control, legitimacy, cohesion and performance (Dubnick and Frederickson 2011). With NPM's emphasis on "hands-on professional management, explicit standards of performance, a greater emphasis on output control, and private-sector management techniques" (Diefenbach 2009, p. 324), oversight shifted from direct, bureaucratic control over processes towards the measurement and monitoring of outcomes (Page 2006), and holding to account for performance against these measures. However, while formal performance accountability has been promoted as a means of controlling practitioners' discretion, performance measurement approaches tend to lead to the prioritisation of some goals, ignoring others (Brodkin 1997). This approach may also obscure maladministration at the expense of transparency at the 'street-level' of practitioners (Brodkin 2008). Consequently, there is recognition in the literature that a paradoxical situation has arisen whereby there is an 'audit explosion' (Power 1994) while at the same time there is an 'accountability deficit' (Mulgan 2014), with a diminishing capacity of representative democracy to hold the executive to account. Hybridity in public organisations compounds this, with uncertainty about accountability definitions, relationships, and the location of power.

\section{3 | CONCEPUTALISING HYBRIDITY: TOWARDS A FOCUS ON HYBRID ACCOUNTABILITY OBLIGATIONS}

The term 'hybrid' (as a noun) refers to "a thing made by combining two different elements" (OED) arising from the Latin hybrida, denoting offspring of mixed breeds, both animal and human. Used to describe the intermingling 
of species in biology or a combination of languages in linguistics, the notion has analytical purchase for conceptualising a type which has to do with two previously recognised classifications. As we are interested in exploring hybrid accountability through an analysis of a new welfare delivery system, we turn to expand on the classificatory schemes relevant to public accountability proposed by Bovens, Schillemans, and Goodin (2014) and Mattei (2016). It is this scheme of categories - specifically pertaining to the phenomena of interest - which we would like to suggest hybridity happens 'to' or 'in' (rather than the public/private hybridity).

Extant research into hybridity in public administration is mainly focused on creating typologies of governance according to traditional public administration categories. Hybridity tends to be seen as the mixing together of traditional public sector principles, such as Weberian bureaucracy, and those taken from the corporate tradition of NPM or newer orientations that favour democratic, horizontal modes of governance (Mair, Mayer, and Lutz 2015; Polzer et al. 2016). To illustrate, approaches to hybrid leadership (Fulop 2012) conceptualise it as the mixing of distribution and control, whilst approaches to hybrid regulation (Kurunmäki and Miller 2011) tend to conceptualise it as the mixing of cooperation-focused policy programmes with restrictive organisational boundaries. Hybridity in professional roles in the public sector (Hendrikx and Gestel 2017; Noordegraaf 2015) is often seen as the mixing of expert and managerial concerns. In the case of accountability, this focus led authors to suggest that public accountability — taken as belonging more to the worlds of bureaucracy and control — is supplemented, undercut, or simply co-exists with 'newer' forms of accountability such as market accountability or social accountability - taken to belong to the 'other category' of corporate autonomy.

A focus on paradigms' interaction in hybrid organisations only takes the analyst so far, and it has been argued that hybridity is applied inconsistently across studies, with some claiming that it lacks conceptual clarity (Mair, Mayer, and Lutz 2015; Polzer et al. 2016). In this vein, Polzer et al. (2016) outline various types of hybridity according to their degree of separation, change over time and pattern of mixing. Mair, Mayer, and Lutz (2015) differentiate between organisational responses of social enterprises, identifying conforming hybrids and dissenting hybrids, whilst Battilana and Lee (2014) conceptualised hybridity across organisational dimensions (e.g., culture, workforce composition, organisational activities). Our analysis is situated with this second line of inquiry, as we are interested in going beyond typologies of public administration terminology and towards a more nuanced conceptualisation of hybridity, in our case - hybridity as it relates to accountability obligations per se.

A central way of approaching accountability is as a mechanism (Bovens, Schillemans, and Goodin 2014). This focuses questions on the "way in which institutional arrangements govern the behaviour of public agents" (p. 8) and is pertinent for our concern with practitioner agency and its relation to governance. In analytical terms, this allows accountability relationships to be analysed based on dimensions corresponding to the following questions: Who is the actor being held to account? To which forum is the account given? What is the account about (e.g., financial outcomes or processes)? By which standards is judgment made? and What is the nature of the relationship between actor and forum? Of the typologies of accountability proposed by Bovens et al. (2014), of interest to this paper is the distinction between formal, vertical accountabilities and informal, horizontal accountabilities. This distinction relates to questions of policy hierarchy and practitioners' discretion as it enables exploring accountability relationships between policy actors and their 'superiors' or those 'above' or 'across' in the chain of answerability. It orients research towards the management and exercise of agency and proposes a framework with which to address questions of hybridity in regards the nature of obligation at the root of accountability relationships.

While public accountability has traditionally consisted of relationships in which the forum is 'above' the actor within the chain of bureaucratic answerability and with which relations were explicit, formal and mandatory, policy practitioners are no longer held to account solely by their public administration supervisors. They now have, or choose, to answer to a plethora of forums. These forums are not directly 'above' the actor, but rather 
consists of stakeholders that might relate to its activities, such as public representative bodies, or fellow public sector organisations that are part of a coordinated welfare system (e.g., social and health care) (Checkland et al. 2013). The relationship with these latter organisations might be voluntary, and the accounts do not necessarily bear formal consequences (Bovens 2007). Some of these relationships have been conceptualised as diagonal relationships, i.e. with organisations such as regulators who might wield sanctions in case of performance failure, but who nonetheless do not form part of a traditional top-down bureaucratic structure.

\section{[Figure 1]}

Below, we suggest that within our case study (a welfare delivery model which combines hybrid organisational forms) the nature of obligation at the root of accountability relations as understood along these lines of formal/informal and vertical/horizontal has been hybridised, and thus rendered uncertain.

\section{4 | CASE STUDY CONTEXT: REORGANISATION OF PRIMARY CARE IN} ENGLAND

Healthcare in England underwent a major reform in 2012. Under the Health and Social Care Act 2012 (HSCA2012) clinically-led organisations called Clinical Commissioning Groups (CCGs) were set-up across England, replacing the managerially-led Primary Care Trusts (PCTs). In effect, the regional, strategic tier of planning was abolished and a new national arm's length body, NHS England (NHSE) (known in statute as NHS Commissioning Board), was created to support the locally-oriented CCGs in commissioning health care services (hospital and community services). There were early concerns over potential conflicts of interest associated with clinical leadership in the public sector, as primary care doctors could potentially be commissioning services that they themselves provide; hence responsibility for commissioning primary care services was given to NHS England, although local CCGs were to have influence and involvement to ensure clinical input.

In practice the commissioning of local primary care services requires local knowledge, and by April 2015 it was clear that this was difficult for a national body such as NHSE. Responsibility for commissioning primary care services was therefore delegated to CCGs. The changes meant that while the national body NHSE retains statuary responsibility for primary care-related welfare functions, their delivery was now delegated to local CCGs. The guidance issued (NHS England 2014b) followed a Post-NPM rationale, suggesting that delegating primary care commissioning responsibilities to CCGs would harness clinical insight and energy, supporting a holistic and integrated approach to population health. These benefits were said to outweigh the risks of conflicts of interest, which would be mitigated by developing 'robust new and transparent [management] arrangements'.

As such, the new system developed in England is a hybrid model of public organisation based on two main counts: it instituted hybrid decision-making (managerial, lay and clinical) and a hybrid governance structure (both national and local).

\section{1 | Clinical, executive and lay decision-making}

CCGs place clinicians, managers and lay members at the heart of decision-making. One of the reform's key aims was to 'liberate' professionals from top-down control, giving them more autonomy and, in exchange, making them more accountable:

The Government's reforms will empower professionals and providers, giving them more autonomy and, in return, making them more accountable for the results they achieve, accountable to patients through choice and accountable to the public at local level (Department of Health, 2010, p. 4) 
Delegation of primary care commissioning required the creation of a corporate decision-making Primary Care Commissioning Committee (PCCC) inside local CCGs. The national body NHSE published a model Terms of Reference for CCGs to use as an example, while leaving the specificities of negotiating the responsibilities of each professional group open. The PCCC arrangement is particularly ambiguous as it sits outside of each CCGs Governing Body - it is directly accountable to NHSE due to its primary care planning function, while officially being a corporate body of the individual CCG organisation.

\subsection{Local governance framework for both autonomy and oversight}

The delegation of primary care commissioning to CCGs attempted to shift decision-making 'downward' to a local level while retaining national oversight and control over health outcomes. This has complicated an already "contested, potentially hybrid, and even contradictory accountability framework" (Mattei 2016, p. 471) as it saw the main bulk of healthcare policy implementation, specification, and operationalisation in primary care in England moving from a Non-Departmental Public Body (NDPB) towards local organisations the members of which are GP practices - the very providers of the services that are to be commissioned.

In terms of their accountability to the public, the Government and Parliament, NHSE is responsible for overseeing local CCGs' performance in the commissioning of services via an accountability framework, the Improvement and Assurance Framework (IAF). Figure 2 depicts the governance arrangements within which the mechanism is embedded. While NHSE sits 'above' CCGs in the delegation chain and is mandated to hold CCGs to account through the IAF, the latter is also the framework based on which NHSE is held to account by representative bodies 'above' it.

[Figure 2]

The IAF was published in 2013 and refreshed in 2015. In 2016, it was modified and strengthened to take "an enhanced and more central place in the overall arrangements for public accountability of the NHS" (NHS England 2016, p. 5). The focus of the modified framework is on 'practical support rather than assurance and monitoring' and CCG are assessed under four domains (Better Health, Better Care, Sustainability, and Leadership) and six clinical priorities (mental health, dementia, learning disabilities, cancer, diabetes, and maternity) comprising 60 indicators across 29 areas.

\section{5 | METHODS AND DATA COLLECTION}

To build a detailed picture of the governance arrangements of this delivery model and be able to describe the specificities involved in hybridity, we contend there is value in exploring the realities of organisational members 'on the ground' (see, e.g., Krøtel and Villadsen 2016). Policy actors, under managerialism, are occupied with the excessive formalisation of organisational processes and spend much of their time engaging with systems of control, audit, inspection and review (Butterfield, Edwards, and Woodall 2004). At the same time, local policy practitioners act as 'civic entrepreneurs' (Durose 2011), working to reconcile national priorities with community demands. Civic entrepreneurs shape policy through engagement with local communities, local knowledge, and a logic of enabling and fixing. As they act to reconcile competing interests, stakeholders, and policies, public sector work become more akin to policy entrepreneurship rather than bureaucracy (Oborn, Barrett, and Exworthy 2011).

To explore this, Brodkin (2008) suggested adopting a 'street-level' approach to accountability. A practice approach provides a framework to analyse accountability from 'inside out', unpacking not only governance structures but also the practices that shape local experience. Indeed, as argued by anthropologists and critical accountants, understanding organizational-level behaviour is at the heart of understanding accountability 
(Strathern 2000). Thus, in this paper we set to bring these elements together. We analyse the performance accountability arrangements instituted to govern a new hybrid service delivery model and explore challenges ensuing during implementation. We focus on the interface between the mechanisms of accountability and their intended or unintended consequences 'on the ground' so to offer a more nuanced, or granular view of the sort of hybridity that exists in these arrangements.

To achieve this and we build on a wider project, commissioned by the Department of Health, to explore the development of primary care co-commissioning in England (McDermott et al. 2018). For this paper, we focus on the implementation and delivery experience of four CCGs across England (Table 1). These organisations were chosen following a national survey of CCGs which included 147 CCGs' application documents, provided to us by NHSE with CCGs' agreement. The four were chosen to provide maximum variety along several dimensions, including: geography (north, south and central England); size; enthusiasm related to uptake of new responsibilities (early adopters vs those more reluctant); and engagement with other national reform initiatives.

[Table 1]

Our data collection and analysis included observation of meetings, interviews with key informants and analysis of documents. Meeting observation comprised attendance at 74 meetings (approx. 111 hours of observation), including a variety of operational and strategic meetings associated with primary care co-commissioning. To fully appreciate the realities of change 'on the ground', we also conducted 42 face-to-face interviews with CCG employees directly involved in welfare planning and decision-making such as the Lay Chair, Primary Care Manager, Head of Contracts, Head of Quality, Head of Estates, Head of Engagement, Local Medical Council representative, and representatives of local public engagement bodies such as Healthwatch. We also interviewed the CCGs' Governing Body Chair, Accountable Officer, and Chief Finance Officer. Document analysis included a detailed analysis of governance and regulatory documents related to primary care co-commissioning, including local documents setting out roles and responsibilities as well as the IAF.

Our analytic approach involved initial thematic coding of both interview transcripts and observational fieldnotes. Initial a priori codes were based upon our appreciation of relevant policy issues and literature, with additional codes arising from the data discussed and agreed by the research team. Coded segments relevant to accountability relationships were then extracted and further scrutinised and related to relevant sections of the examined documents. Together, these served to construct an understanding of the regulatory framework governing CCGs' operation and its relation to broader questions of public sector hybridity. The following sections are based upon this extensive analysis, with data extracts provided which illustrate the points made.

\section{6 | HYBRID ACCOUNTABILITY OBLIGATIONS IN CCGS}

When considering the governance model of CCGs using the framework of public accountability, it becomes difficult to pinpoint accountability obligations in a clear manner. The accountability actor is clearly defined as the CCG, with the off-the-board PCCC taking on the role on behalf of the organisation. Information sources for performance monitoring (the What question of accountability) and consequences of failing to provide assurance are also clear, with the IAF setting out a wide range of performance metrics and a variety of potential interventions should these not be achieved. Nonetheless, whilst accountability with regards outcomes may be clear, the IAF and other associated CCG governance mechanisms introduce uncertainty in terms of the accountability obligations to a forum. Our first main finding is that accountability becomes hybrid as it places the accountability actor in a dual-nature relationship with its various stakeholders. We turn to explore this in more depth. 


\section{1 | Vertical forums, horizontal relationships: Informalising formal obligations}

CCGs operate in the field of primary care commissioning by power of delegation, with NHSE retaining the statutory responsibility for this function. Thus, their main accountability forum is NHSE. The accountability obligation between the two would thus be expected to be vertical and formal. That is, it might be expected that NHSE would be 'above' CCGs in the chain of answerability and that the account given by CCGs to the national body is mandatory, explicit and formalised.

However, where one would expect to find clear demarcations that could limit discretion and manage the way policy might be shaped 'at the street-level' by practitioners, in practice the accountability mechanism is promoted in relevant documents as a conversational tool: "The framework is intended as a focal point for joint work, support and dialogue between NHS England and CCGs" (NHS England 2016, p. 8). Instead of using an authoritative language that marks how CCGs' autonomy is to be limited by the accountability mechanism, the IAF document speaks of "providing indicators for adoption" (p.2) or providing "a reasonable degree of balance in illuminating the future agenda" (p. 6). In a Post-NPM managerial style, NHSE stated intentions in designing the framework are to "empower CCGs to deliver the transformation necessary to achieve [service improvement]" and its focus is "therefore on practical support, rather than assurance and monitoring" (p.10). This vague and convoluted description makes it hard to consider this accountability mechanism as a framework at all, leaving much to be desired in terms of formalising the relationship between NHSE and the organisations to which it has delegated authority. Consequently, the formality that is meant to limit the manoeuvrability of front-line policy implementers becomes reliant on human judgement as it is acknowledged that "a critical factor in the success of the new framework will be the quality of the relationships between the NHS England local teams and CCGs." (p.8)

The reliance on relationships as a guarantor for what would usually be a formal accountability relationship is of relevance because of the nature of CCGs. As mentioned, CCGs were specifically set up as clinically-led organisations which would take over the responsibilities previously held by managerially-led Primary Care Trusts, with many managers leaving their posts in the transition. With this loss of expertise, and the continuing uncertainty about the distribution of responsibilities in the new system, individuals' past experiences and relationships became pivotal for their day-to-day work. This was particularly evident as CCG staff struggled to maintain a relationship with the national body NHSE, especially during the turbulent initial period of taking over new welfare responsibilities.

Thus, accountability obligations became hybrid as governance arrangements manifested a formal accountability forum that articulates its demands as if it was informal. This was exemplified by a manager, seconded from NHSE to work in a CCG, who describes the importance of 'who to call':

I do think [my past experience with NHSE] has been advantageous, because I've got a good relationship, [I'm] still employed by NHS England, where you do find an issue you can work through that with somebody that you know and somebody that you trust. I think we're quite open at being able to pick up the phone to each other and saying oh, you might have missed this or you need to do that. [Manager IDIO]

The relationship between the accountability forum and the accountability actor became dependent on past relationships of the individual manager, facilitated by the hybrid employment model of secondment from NHSE to the CCG. Such dependence on informal relationships (an employee happens to be seconded, thus allowing for better compliance on the part of the CCG) was repeated many times in our data, with managers in both interviews and observed meetings drawing on their personal and past acquaintances and skills to carry out their roles. This 
may have detrimental consequences on operations, and thus on CCGs ability to meet their accountability outcomes, as much of what CCGs do depend on prior approval or input from the national body:

I think they're suffering perhaps, NHSE, generally suffering from the lack of capacity to react and respond quickly and efficiently... Today was an example of that. NHSE has been silent for the last two months on certain issues that we've been raising, whether it's TB screening or whether it's flu vaccinations, whatever, or asylum seekers and refugees, and NHSE has been absent. (Lay member, ID14)

With CCGs decision-making depending on an NHSE under pressure, their ability to function becomes dependant on prior, individual relationships with NHSE rather than a formalised, structured relationship. As observed during executive meetings in CCG-B, for example, the Risk Register was frequently filled with issues presumably under CCG control awaiting an NHSE response, clearly marking the relationship with the national body as a risk factor due to uncertainty.

Thus, with a design underpinned by a partnership rationale (as set out in the IAF documents), and exacerbated by the lack of primary care expertise in CCGs, in practice the latter are simultaneously 'below' but also equal hence horizontal (informal) - partners to NHSE (figure 3), making accountability obligations hybrid, a case of both-and.

\section{[Figure 3]}

\section{2 | Horizontal forums, vertical relationships: Formalising informal obligations}

As well as hybridising accountability obligations between CCGs and NHSE, the IAF further hybridises accountability by blurring the boundaries of formality and informality between CCGs and other healthcare bodies, first and foremost its membership. The IAF sets out how vertical accountability is meant to be operationalised i.e., how NHSE as the delegating body will hold the delegated body to account. However, as mentioned, CCGs are membership organisations with members being GP practices. Thus, the dynamic between the national body NHSE and the welfare delivery organisations has changed with the delegation of responsibility for primary care commissioning:

Well it goes back to earlier conversation, doesn't it, around membership organisations? I guess all the time that [primary care] was commissioned by NHS England and if you're sat as a GP member on the governing body or you're a GP practice who want to do what they want, if primary care wasn't what you wanted it to be, you could all [i.e. executive and membership] be on exactly the same side and say that terrible NHS England aren't very good at this, are they? .... I guess the bit that could change is now it's delegated, I think our governing body and members will feel accountable to all of their membership who are absolutely passionate about improving primary care and we now have the tools to do it, we have the budget to do it, it is our local decisions. So that feels a bit more like the membership are going to hold us to account, that's something they're really passionate about (Manager ID42).

Thus, while NHSE is the vertical forum with formal responsibility to hold CCGs to account over primary care, the place of the membership is unclear. For one, they might be considered as stakeholders within the framework of public accountability, thus forming an informal, horizontal obligation with the CCGs. But with GPs and GP practices formally members of CCGs, this relationship is fuzzy, and there is a formal expectation, and even motivation, to be held to account. Instead of a clear demarcation between the formal obligations to bodies 'above' it in the chain of answerability, CCG practitioners are also formally obligated towards their service delivering 
members, with a set of constitutional documents establishing relevant roles and responsibilities. This was evident in our observation of CCG meetings, in which 'the membership' figured as an important accountability forum, always present as an invisible and assumed audience for discussions and decisions who could, according to CCGs' constitutions, remove CCG officers with whom they were displeased. It also featured in interviews, whereby CCG members have taken an almost formalized role in commissioning planning:

Up until this year we had seven commissioning networks which we funded from the member[ship]. Through the membership they agreed on the configuration. It is seven geographical areas with a clinical chair that we funded and they...that was the membership. We called it membership led commissioning. So that was them, on our behalf, identifying areas to transform and we gave them each a theme. (Manager ID12)

Furthermore, the performance accountability mechanism states that assessment of CCGs compliance will rely on information provided by organizations that are not vertically 'above' CCGs within the delegation chain, including neighbouring CCGs, local Healthwatch (responsible for patient voice), or Local Authorities (via Health and Wellbeing Boards). In practice, the way in which CCGs decide to operationalise their mandate over welfare delivery will be judged by those organisations and will affect the judgement made by NHSE about CCGs' performance. While CCGs' main accountability is vertically to NHSE, the IAF ties the satisfaction of local partners into the accountability mechanism and creates a situation in which clear prioritisation between national policies and local arrangements is not clear. These bodies that do not stand 'above' CCGs in terms of control and command nor do they have precedence in terms of policy formulation, but nonetheless are named in the IAF as sources of 'insight' upon which NHSE will (or will not) establish its confidence in a CCG. The lack of a clear demarcation of authority between CCGs' actions and other bodies in the system (Gore et al. 2018) makes it particularly difficult for managers to judge how and in what capacity stakeholders should be taken into consideration. While 'diagonal accountability' has been proposed as additional conceptualisation of prevailing relations, the latter is about a formalised relationship between public bodies and other agencies, usually regulators who are not 'above' them in the delegation chain (Schillemans 2015). In this case, by contrast, the IAF takes nonregulatory stakeholders into account in a formalised way. It thus ends up formalising informal, horizontal relationships, introducing ambiguity and hybrid accountability like that observed in the relationship between CCGs and NHSE.

[Figure 4]

\section{7 | HYBRID ACCOUNTABILITY OBLIGATIONS AND PRACTITIONER} DISCRETION

Our second main finding is that within this new hybrid delivery model, hybrid accountability obligations have become a source of practitioner discretion as CCG practitioners gained control and discretion over organisational practices that are external to the domain of healthcare, namely over the very domain of governance arrangements, the management of conflict of interest, and the distinction between what constitutes private and public matters. In this respect, Schillemans and Busuioc (2015) have observed behaviours of 'forum drift' by which the accountability forum chooses, for this reason or another, not to hold an accountability actor to account. In our case, the accountability forum - NHSE - does choose to hold public practitioners to account, but, importantly, and due to motivations in line with 'new' administrative logics of inter- and intra-organisation cooperation and accommodation, hybrid accountability leads to a kind of 'forum drift' whereby practitioner discretion is being extended rather than controlled. Even though the IAF, as a performance accountability mechanism, is meant to 
restrict discretion by specifying the health outcomes expected from CCGs (patient choice, mortality rates, diabetes, access to services, etc.), it is also the same mechanism that measures CCGs on the quality of their governance and oversight arrangements (e.g., how they operationalise conflicts of interest). This means that the governance structures of welfare delivery are included as one of the performance outcomes CCGs are monitored on. With unclear relationships and lack of detail, the PCCC, an executive committee comprising managers, GPs, and lay representatives, ended up deciding on matters which are at the heart of the relationship between the state and the citizen: what is a private affair; what might be regarded as a conflict of interest; or who is involved in welfare planning decision making.

\section{1 | Discretion over governance structure}

The first managerial discretion drift has to do with the structures of welfare delivery. In exercising their primary care co-commissioning delegated functions, CCGs are required to establish a corporate decision-making Primary Care Commissioning Committee (PCCC). NHSE has published a model Terms of Reference (ToR) for this committee, but it does not dictate the what should be included in a PCCC ToR. Hence CCGs are given the flexibility to articulate their PCCC's responsibilities, its membership, quorum, schedules, geographic coverage, meetings frequency, procurement, and decision-making. While this leaves room for local specificity and expert input, this also generates ambiguity in relation to what is expected from CCGs, or how best to define responsibilities, domains of operation, and lines of accountability. The hybrid nature of obligation to NHSE and additional stakeholders, together with the fact that the accountability mechanism does not specify the standards by which governance arrangements are to be judged lead to a situation in which CCGs have to use their discretion on these issues - they had to come up with their own structures for welfare delivery. This was evident when considering the governance structure put in place by each CCG (set out in Table 2) (Correct at time of data collection; may have changed since).

(1)

[Table 2]

Thus, in practice, the setting up of primary care co-commissioning functions within CCGs has generated different approaches, designs, and ways of working with each CCG developing internal procedures that fit with its historical contingencies and local stakeholders. CCG executives, in-charge of health-related outcomes, were also able to choose whether, for example, decisions about health care should be made every month or quarterly. More importantly, they get to decide on who needs to be present for a quorum to be met, whether to invite the Local Medical Council representative, or which members of the CCG executive get to vote.

\section{2 | Discretion over conflict-of-interest policy implementation}

The IAF requires CCGs to submit an annual self-certification that they have a 'clear' conflict of interest management policy in place. This legislative framework (section 140 of the Act) sets out the minimum requirements in terms of what CCGs must do in terms of managing conflicts of interest, and NHSE published guidance for CCGs. This guidance, stated, amongst other things, that CCGs must maintain registers of interest, make arrangements for public access to those registers, and "make arrangements requiring the prompt declaration of interests by the persons specified (members and employees) and ensure that these interests are entered into the relevant register" (NHS England 2014a, p. 10). Part of the IAF, then, is to judge whether CCGs are meeting these guidelines. As opposed to health outcomes for which the performance accountability mechanism is highly specific, the IAF does not offer any details about the standards by which 'good' governance is to be evaluated. CCGs need to provide assurance as to the existence of 'effective systems [...] to ensure compliance with [their] statutory functions', but what this actually entails is left unspecified. This is of particular importance in the case of 
CCGs as the organisational governance arrangements for the delivery of primary care co-commissioning were either not specified exhaustively by NHSE and the government or, when specified, created a 'structural conflict of interest' that is very hard to manage (Moran et al. 2017).

The management of conflicts of interest was a prominent feature of our observations. Our case study sites adopted different approaches. All our case study CCGs maintained and/or published a Register of Interests on their websites. Three of our case study sites additionally published a Register of Gifts and Hospitality. One site recruited GPs from an outside area so to ensure impartiality of professional input, whilst other sites either included GP members who hold different contracts or included GPs as non-voting members to ensure the clinical voice was not lost when the local GP members must leave the room during discussions which present conflicts of interest. We observed how CCGs initially encountered difficulty in defining who are the "members and employees" who should declare interest. The guidance was ambiguous and did not make clear who are the "persons specified (members and employees)", as described by one of our interviewees:

Well, before what we did was we only looked at people involved in commissioning from member practices [...]. We didn't have a register of all GP partners. The new guidance is every single member of staff, whether they're a GP or whether they're a cleaner, they will be declaring their address and they'll be published. [Manager ID13]

We also observed the ambiguity over the definition of "close relative and close friends" and how members of the committee made sense of this ambiguity with considerable time in meetings devoted to discussing these issues. Another recurring theme across our case study sites was around risk registers. Although what was on the register can be briefly discussed in public meetings, the details of the risks may contain 'sensitive', 'confidential', and/or 'controversial' information which could be interpreted as politically sensitive such as closure of a GP practice or the quality of provider services. Hence distributions of this type of information were carefully managed to avoid misinterpretation and managers used their discretion over what constituted 'good' governance in this domain.

\subsection{Discretion over transparency and publicity}

The Terms of Reference for delegated commissioning stipulates that primary care co-commissioning meetings should be held in public (as distinct from being public meetings) but also make provision to exclude the public from meetings in circumstances such as:

whenever publicity would be prejudicial to the public interest by reason of the confidential nature of the business to be transacted or for other special reasons stated in the resolution and arising from the nature of that business or of the proceedings or for any other reason permitted by the Public Bodies (Admission to Meetings) Act 1960 as amended or succeeded from time to time. (NHS England 2014b)

The requirement to hold these meetings in public has created the need for the committee to discuss some of their agenda items in private. Our case study CCGs divided meetings into 'public' (where members of the public could attend) and 'private' (where members of the public were excluded). This has caused dilemma around the notions of what can and should be discussed in public and what in private. This again was a prominent feature of the meetings we observed. In general, when in doubt members of the committee would defer to the Chair of PCCC for clarification, move the discussion to the private section of the meeting at the Chair's discretion, or take the discussion 'out of the room'.

We also saw managers' discretion in discussions about how to manage information coming to PCCC public meetings from Operational Groups that hold private meetings. Framing reports to overcome the incongruence of

This article is protected by copyright. All rights reserved. 
simultaneously being communicative and transparent but respectful of confidential and sensitive information was a source of confusion as the following extract illustrates:

Chair of Audit Committee: These [PCOG - Primary Care Operational Group] notes don't say much!

Primary Care Contract Support: PCOG is not a public meeting. The PCCC is and the material is in the public domain.

Governance Support: Sensitive information can be discussed in PCOG. If we receive a Freedom of Information request, then we need to provide it all.

Chair of Audit Committee: I don't understand.

NHSE representative: Something just being sensitive or awkward doesn't justify.

Chief Finance Officer: we'll have a think about the mechanics. [Primary Care Commissioning Committee meeting, M42]

Despite the anxiety surrounding public meetings, all our case study CCGs attempted to make the agenda and papers for PCCC meetings publicly available. However, there were occasions where these were not available in advance of the meetings. On the other hand, even when public meetings were advertised, members of the public did not always attend. The lack of public attendance had consequently led one of our case study sites to run some of their meetings in an informal way by mixing their public and private discussions in an informal order, contingently and in an emergent manner. Thus, the hybrid accountability mechanism extended practitioners (in our case, managers) discretion into the domain of governance.

\section{8 | CONCLUSION}

In this paper, we joined calls for the further specification of what hybridity might mean in the context of accountability. Rather than asking about accountability within hybrid organisations or hybrid welfare structures alone, we proposed to ask about accountability itself and the ways it could be understood as hybrid within a case study of reform. In our case, a new delivery model aimed at 'liberating' professionals by situating clinicians at the centre of healthcare planning and commissioning resulted in a situation of hybrid obligations in which accountability forums were both in a position of a vertical and a horizontal relationship with the accountability actor. Interestingly, such hybridisation of obligations, whereby uncertainty reigns over expectations and responsibilities, opened spaces for practitioner's manoeuvrability which are directly related to the notion of democratic accountability and the boundaries of the public sector. Due to the uncertainty inherent in the model, in practice it became a matter for practitioners working within locally formed, locally-oriented, member-led, and, more importantly, unelected organisations to decide on the shape and detail of healthcare commissioning governance structures. While granting professionals more discretion in shaping policy and its implementation might be an intended result of reform, it is important to note that under-articulation of the structures of governance and the demands directed at those gaining further discretion can lead to what we termed 'managerial discretion drift' and the dislocation of discretion to additional elements within the welfare system. This has direct bearing to public accountability, as it becomes harder for the public to realise why welfare delivery models take the shape they do, and due to whose involvement.

Our analysis, thus, further unpacks our understanding of hybrid accountability by suggesting a focus on accountability obligations as the analytical 'grid' within which hybridity happens. It points to the fruitfulness of asking about hybridity in relation to the analytical frameworks of accountability already developed in the literature, in our case that of Public Accountability, and offers insights into the unintended consequences of hybridity and its possible effects on practitioners' response to hybrid obligations. Moreover, our focus on

This article is protected by copyright. All rights reserved. 
obligations hybridity and the findings it generated lead to two contributions to the scholarly discussion of accountability: one in terms of extending our understanding of circumstances in which a diminishing public accountability might occur, and second in terms of the domains to which hybridity happens.

In relation to the broader discussion of accountability in the public sector, the focus on hybrid accountability obligations enabled us to present findings that further support a diminishing of public accountability, while pointing to new avenues through which this phenomenon might occur. Accountability scholarship has demonstrated how public bodies are today subject to conflating demands posed by ever growing webs of accountability (Page, 2006). With extant research mostly focused on goal disparity between stakeholders or between the kinds of accountability concurrent stakeholder might ask for, the diminishing of public accountability is usually attributed to the pull of different organisations. In this vein, previous work demonstrates how demands for political accountability posed by one stakeholder might be in conflict with the demands for vertical accountability posed by others (Kim 2017), how local stakeholders might pose rival demands to those enacted through regulation bodies, or how the very fabric of the executive branch is now fragmented into various agencies posing contradictory obligations on their clients/constituent organisations (Radin, 2010). By focusing on the issue of hybrid accountability obligations, our findings add to these accounts by demonstrating how the very same organisation, in our case both NHSE and local stakeholders, might pose accountability obligations that are themselves hybrid, not clearly demarcated in terms of their formality and informality or the extent to which they are mandatory. This suggests that even in cases whereby no new organisations have been introduced, there might still be a diminishing of public accountability. We encourage further empirical investigation of this avenue.

\section{References}

Agranoff, Robert. 2007. Managing within Networks: Adding Value to Public Organizations. Georgetown University Press.

Battilana, Julie, and Matthew Lee. 2014. “Advancing Research on Hybrid Organizing - Insights from the Study of Social Enterprises.” The Academy of Management Annals 8(1): 397-441. https://doi.org/10.1080/19416520.2014.893615.

Behn, Robert D. 1998. "The New Public Management Paradigm and the Search for Democratic Accountability." International Public Management Journal 1(2): 131-164. http://www.sciencedirect.com/science/article/pii/S1096749499800889.

Bovens, Mark. 2007. "Analysing and Assessing Accountability: A Conceptual Framework.” European law journal 13(4): 447-68.

Bovens, Mark, Thomas Schillemans, and Robert E Goodin. 2014. "Public Accountability." http://www.oxfordhandbooks.com/view/10.1093/oxfordhb/9780199641253.001.0001/oxfordhb9780199641253-e-012.

Boyce, Gordon, and Cindy Davids. 2009. "Conflict of Interest in Policing and the Public Sector." Public Management Review 11(5): 601-40.

http://www.tandfonline.com/doi/abs/10.1080/14719030902798255 (May 17, 2018).

Brodkin, Evelyn Z. 1997. "Inside the Welfare Contract: Discretion and Accountability in State Welfare Administration." Social Service Review 71(1): 1-33.

http://www.journals.uchicago.edu.manchester.idm.oclc.org/doi/abs/10.1086/604228.

- 2008. "Accountability in Street-Level Organizations." International Journal of Public

Administration 31(3): 317-36. http://www.tandfonline.com/doi/abs/10.1080/01900690701590587.

Butterfield, Reginald, Christine Edwards, and Jean Woodall. 2004. "The New Public Management and

This article is protected by copyright. All rights reserved. 
the UK Police Service." Public Management Review 6: 395-415.

Checkland, Kath et al. 2013. "Accountable to Whom, for What? An Exploration of the Early

Development of Clinical Commissioning Groups in the English NHS.” BMJ Open 3(12): e003769. http://bmjopen.bmj.com/content/3/12/e003769.

Christensen, Tom, and Per Lægreid. 2011. "Complexity and Hybrid Public Administration-Theoretical and Empirical Challenges.” Public Organization Review 11(4): 407-23.

https://link.springer.com/article/10.1007/s11115-010-0141-4.

Denis, Jean-Louis, Ewan Ferlie, and Nicolette Van Gestel. 2015. "Understanding Hybridity in Public Organizations." Public Administration 93(2): 273-89.

http://onlinelibrary.wiley.com/doi/10.1111/padm.12175/abstract.

Diefenbach, Thomas. 2009. "NEW PUBLIC MANAGEMENT IN PUBLIC SECTOR ORGANIZATIONS: THE DARK SIDES OF MANAGERIALISTIC 'ENLIGHTENMENT.'” Public Administration 87(4): 892-909. http://doi.wiley.com/10.1111/j.1467-9299.2009.01766.x.

Dubnick, Melvin J., and H. George Frederickson. 2011. Kettering Foundation Public Accountability: Performance Measurement, the Extended State and the Search for Trust. Rochester, NY: National Academy of Public Administration \& The Kettering Foundation.

https://papers.ssrn.com/abstract $=1875024$.

Durose, Catherine. 2011. "Revisiting Lipsky: Front-Line Work in UK Local Governance." Political Studies 59(4): 978-95. http://journals.sagepub.com/doi/10.1111/j.1467-9248.2011.00886.x.

Fulop, Liz. 2012. "Leadership, Clinician Managers and a Thing Called 'Hybridity." Journal of Health Organization and Management 26(5): 578-604.

http://www.emeraldinsight.com/doi/full/10.1108/14777261211256927.

Gore, Oz et al. 2018. "Not Every Public Sector Is a Field: Evidence from the Recent Overhaul of the English NHS.” Public Management Review: 1-22.

https://www.tandfonline.com/doi/full/10.1080/14719037.2018.1503703 (September 10, 2018).

Hendrikx, Wiljan, and Nicolette van Gestel. 2017. "The Emergence of Hybrid Professional Roles: GPs and Secondary School Teachers in a Context of Public Sector Reform." Public Management Review 19(8): 1105-23. https://doi.org/10.1080/14719037.2016.1257062.

"Hybrid." Oxford English Dictionary. http://www.oed.com/view/Entry/89809.

Kim, Yoonho. 2017. "Analyzing Accountability Relationships in a Crisis: Lessons From the Fukushima Disaster." The American Review of Public Administration: 027507401772422. http://journals.sagepub.com/doi/10.1177/0275074017724224 (August 29, 2018).

Krøtel, Sarah M.L., and Anders R. Villadsen. 2016. "Employee Turnover in Hybrid Organizations: The Role of Public Sector Socialization and Organizational Privateness.” Public Administration 94(1): 167-84. http://doi.wiley.com/10.1111/padm.12211 (September 10, 2018).

Kurunmäki, Liisa, and Peter Miller. 2011. "Regulatory Hybrids: Partnerships, Budgeting and Modernising Government.” Management Accounting Research 22(4): 220-41. http://www.sciencedirect.com/science/article/pii/S1044500510000703.

Mair, Johanna, Judith Mayer, and Eva Lutz. 2015. "Navigating Institutional Plurality: Organizational Governance in Hybrid Organizations.” Organization Studies 36(6): 713-39. https://doi.org/10.1177/0170840615580007.

Mattei, Paola. 2016. "Public Management Reforms and Their Impact on Democratic Processes." In Public Accountability and Health Care Governance, London: Palgrave Macmillan, 1-11.

McDermott, Imelda et al. 2018. Understanding Primary Care Co-Commissioning: Uptake, Development, and Impacts. Final Report. Manchester. http://blogs.lshtm.ac.uk/prucomm/files/2018/03/PCCC-final-report-v11-final.pdf. 
Mcgivern, Gerry et al. 2015. "Hybrid Manager-Professionals' Identity Work: The Maintenance and Hybridization of Medical Professionalism in Managerial Contexts." Public Administration 93(2): 412-32. https://onlinelibrary.wiley.com/doi/abs/10.1111/padm.12119.

Van Meter, Donald, and Carl E Van Horn. 1975. "The Policy Implementation Process: A Conceptual Framework." Administration \& Society 6(4): 445-88. https://doi.org/10.1177/009539977500600404.

Moran, Valerie et al. 2017. "How Are Clinical Commissioning Groups Managing Conflicts of Interest under Primary Care Co-Commissioning in England? A Qualitative Analysis." BMJ open 7(11): e018422. http://www.ncbi.nlm.nih.gov/pubmed/29122801 (May 21, 2018).

Mulgan, Richard. 2014. "Accountability Deficits." In The Oxford Handbook of Public Accountability, eds. Mark Bovens, Robert E Goodin, and Thomas Schillemans. 10.1093/oxfordhb/9780199641253.013.0010.

Newberry, Susan. 2015. "Public Sector Accounting: Shifting Concepts of Accountability." Public Money \& Management 35(5): 371-76. http://www.tandfonline.com/doi/full/10.1080/09540962.2015.1061180.

NHS England. 2014a. Managing Conflicts of Intrest: Statutory Guidance for CCGs. https://www.bma.org.uk/-/media/files/pdfs/practical advice at work/commissioning/dec 2014 - nhs england statutory guidance ccg coi commissioning.pdf.

- 2014b. "Next Steps towards Primary Care Co- Commissioning." (November): 1-48. http://www.england.nhs.uk/commissioning/pc-co-comms/. . 2016. CCG Improvement and Assessment Framework 2016/17: Technical Annex. https://www.england.nhs.uk/commissioning/wp-content/uploads/sites/12/2016/05/technicalannex.pdf.

Noordegraaf, Mirko. 2015. "Hybrid Professionalism and beyond: (New) Forms of Public

Arofessionalism in Changing Organizational and Societal Contexts." Journal of Professions and Organization 2(2): 187-206. https://academic.oup.com/jpo/article/2/2/187/1821658.

Oborn, Eivor, Michael Barrett, and Mark Exworthy. 2011. "Policy Entrepreneurship in the Development of Public Sector Strategy: The Case of London Health Reform.” Public Administration 89(2): 32544. http://www.ncbi.nlm.nih.gov/pubmed/22069793.

Olsen, Johan P. 2009. "Change and Continuity: An Institutional Approach to Institutions of Democratic Government." European Political Science Review 1(01): 3. http://www.journals.cambridge.org/abstract_S1755773909000022.

Overman, Sjors, and Sandra van Thiel. 2016. "Agencification and Public Sector Performance: A Systematic Comparison in 20 Countries." Public Management Review 18(4): 611-35. https://doi.org/10.1080/14719037.2015.1028973.

Page, Stephen. 2006. "The Web of Managerial Accountability: The Impact of Reinventing Government.” Administration \& Society 38(2): 166-97. https://doi.org/10.1177/0095399705285990.

Polzer, Tobias, Renate E Meyer, Markus A Höllerer, and Johann Seiwald. 2016. "Institutional Hybridity in Public Sector Reform: Replacement, Blending, or Layering of Administrative Paradigms.” In How Institutions Matter!, Research in the Sociology of Organizations, Emerald Group Publishing Limited, 69-99. http://www.emeraldinsight.com/doi/full/10.1108/S0733-558X201600048B003. Power, Michael. 1994. The Audit Explosion. London: Demos.

Radin, B A. 2010. "Does Performance Measurement Actually Improve Accountability?" In Accountable Governance: Problems and Promises, eds. M J Dubnick and H G Frederickson. New York: M.E. Sharpe, 98-110. 
Schillemans, Thomas. 2015. "Managing Public Accountability: How Public Managers Manage Public Accountability." International Journal of Public Administration 38(6): 433-41. http://www.tandfonline.com/doi/full/10.1080/01900692.2014.949738.

Schillemans, Thomas, and Madalina Busuioc. 2015. "Predicting Public Sector Accountability: From Agency Drift to Forum Drift." Journal of Public Administration Research and Theory 25(1): 191215. https://academic.oup.com/jpart/article/25/1/191/889031.

Strathern, Marilyn. 2000. Audit Cultures: Anthropological Studies in Accountability, Ethics and the Academy. London and New York: Routledge.

Streeck, Wolfgang, and Kathleen Thelen. 2005. Beyond Continuity: Institutional Change in Advanced Political Economies. Oxford, New York: Oxford University Press.

Turner, Simon, Ana LourenÇo, and Pauline Allen. 2016. "HYBRIDS AND PROFESSIONAL COMMUNITIES: COMPARING UK REFORMS IN HEALTHCARE, BROADCASTING AND POSTAL SERVICES." Public Administration 94(3): 700-716.

http://doi.wiley.com/10.1111/padm.12256 (September 10, 2018).

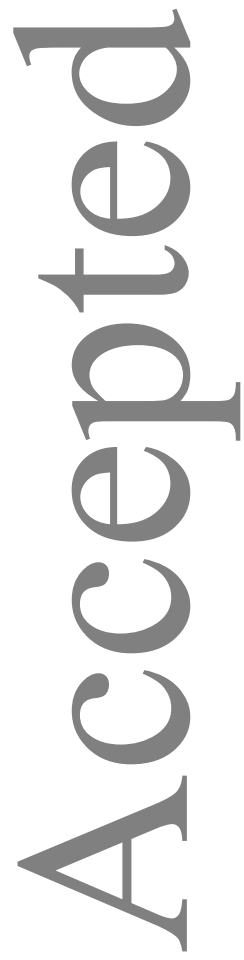




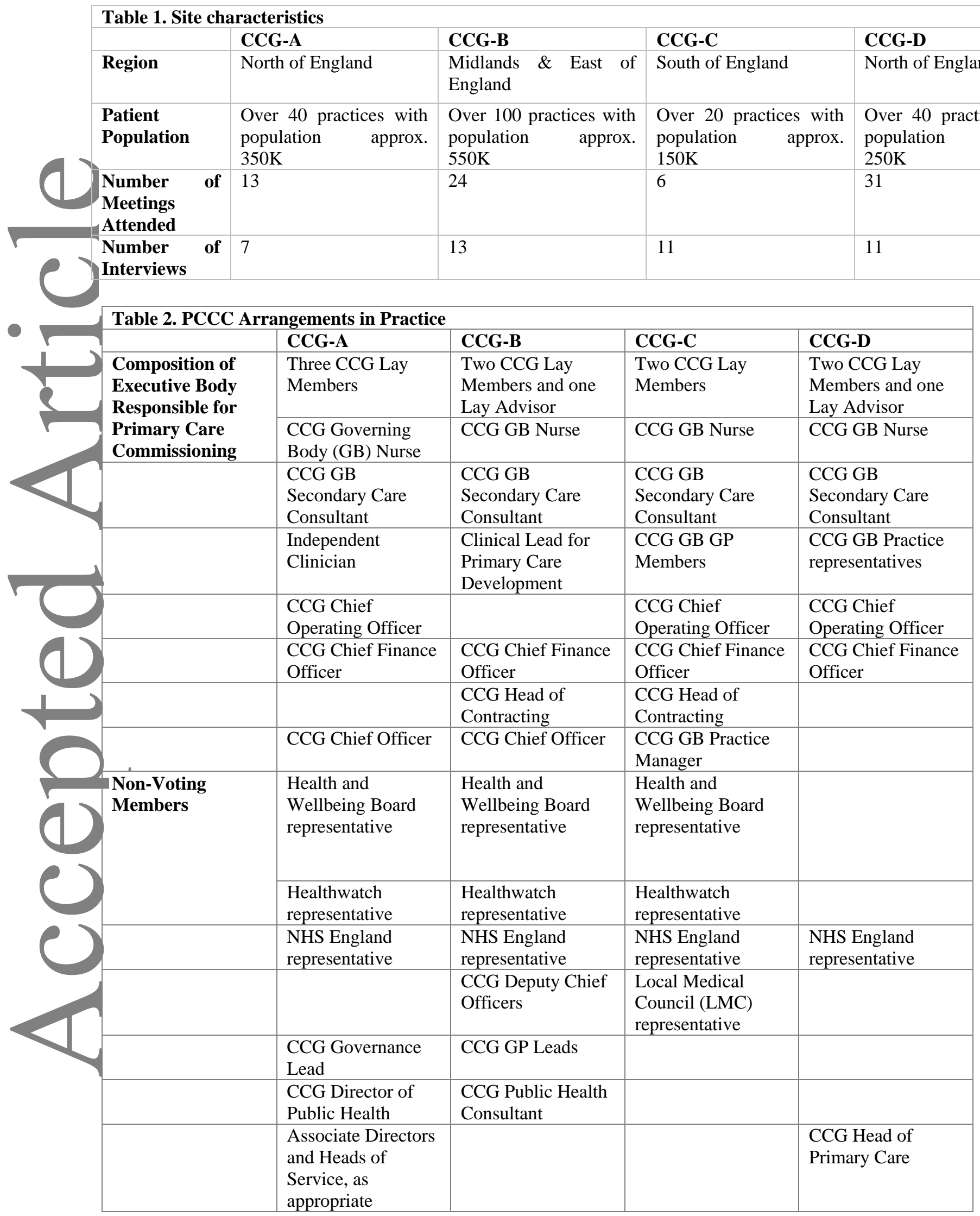




\begin{tabular}{|c|c|c|c|c|}
\hline \multirow[t]{3}{*}{ Invited/Observer } & & $\begin{array}{l}\text { Local Medical } \\
\text { Council (LMC) } \\
\text { representative }\end{array}$ & & $\begin{array}{l}\text { Local Medical } \\
\text { Council (LMC) } \\
\text { representative }\end{array}$ \\
\hline & & & & $\begin{array}{l}\text { Health and } \\
\text { Wellbeing Board } \\
\text { representative }\end{array}$ \\
\hline & & & & $\begin{array}{l}\text { Healthwatch } \\
\text { representative }\end{array}$ \\
\hline $\begin{array}{l}\text { Quorum } \\
\text { Requirements }\end{array}$ & $\begin{array}{l}\text { Three members } \\
\text { must be present and } \\
\text { this must include; a } \\
\text { Lay Member and } \\
\text { either Chief Officer } \\
\text { or Chief Finance } \\
\text { Officer or Chief of } \\
\text { Service Delivery } \\
\text { and Quality }\end{array}$ & $\begin{array}{l}\text { At least three Non- } \\
\text { Executive } \\
\text { members, } 1 \mathrm{GP}, 2 \\
\text { CCG Chief } \\
\text { Officers, Chief } \\
\text { Finance Officer, } \\
\text { Head of } \\
\text { Contracting, and } \\
\text { any } 2 \text { non-voting } \\
\text { members. }\end{array}$ & $\begin{array}{l}\text { One Lay Member, } \\
\text { one GP, and one } \\
\text { Executive member. }\end{array}$ & $\begin{array}{l}\text { Four members } \\
\text { present and this } \\
\text { must include; Chief } \\
\text { Officer or Chief } \\
\text { Finance Officer and } \\
\text { two of the } \\
\text { following: Lay } \\
\text { Member (Audit or } \\
\text { Patient and Public } \\
\text { Involvement), } \\
\text { Nurse, or } \\
\text { Secondary Care } \\
\text { Consultant. }\end{array}$ \\
\hline Schedule & Quarterly & $\begin{array}{l}\text { Monthly; minimum } \\
\text { of } 10 \text { meetings a } \\
\text { year }\end{array}$ & $\begin{array}{l}\text { No less than } 5 \text { times } \\
\text { a year }\end{array}$ & Every month \\
\hline
\end{tabular}

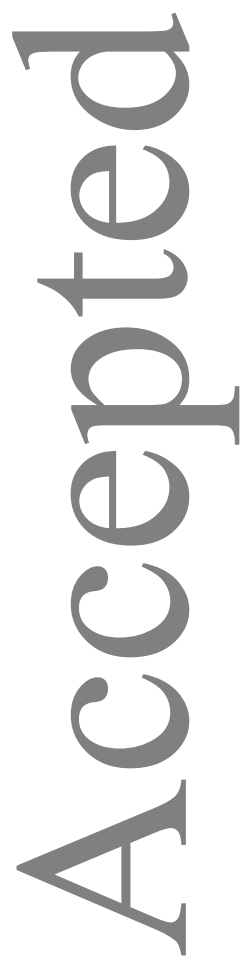




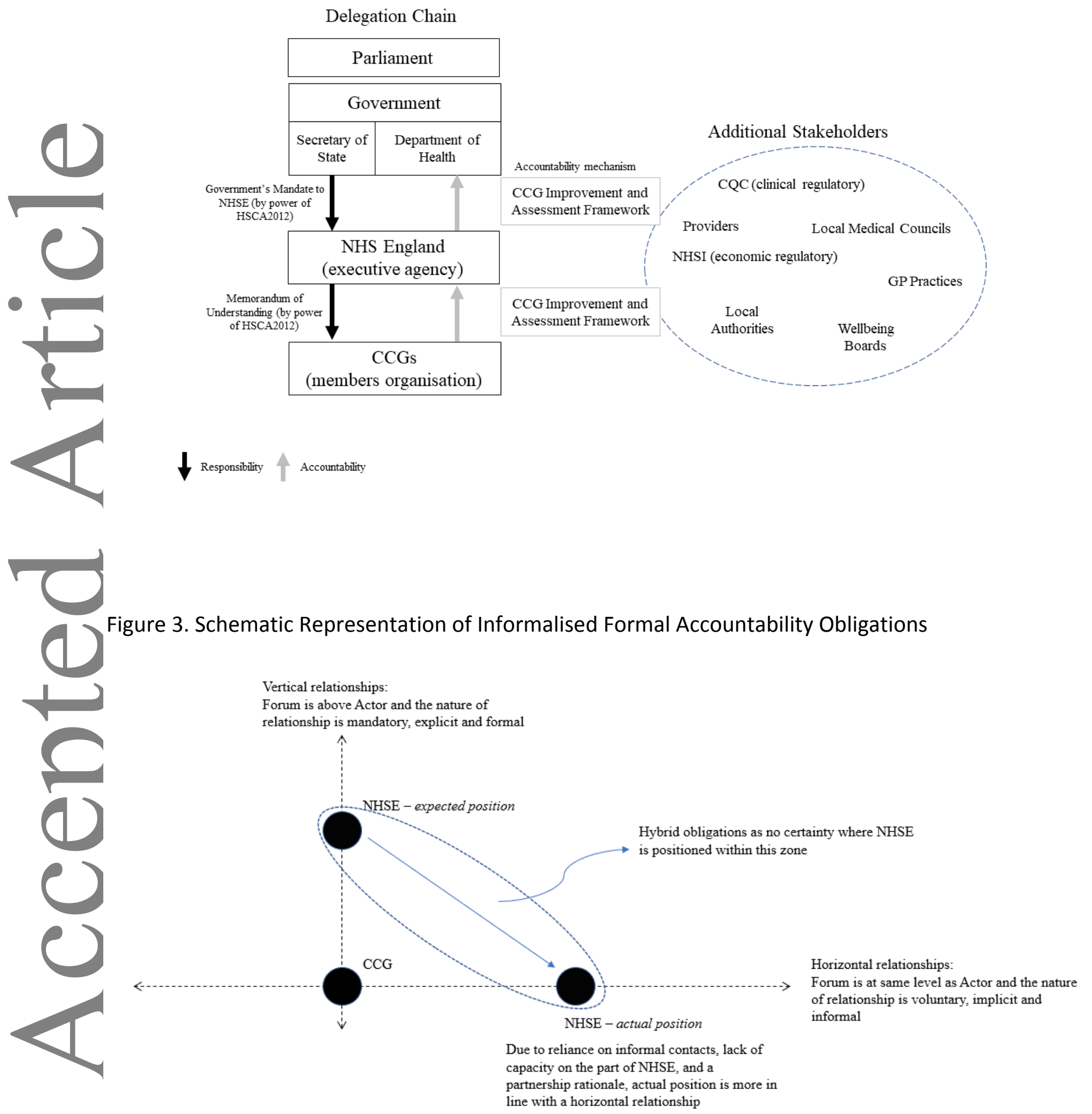

This article is protected by copyright. All rights reserved. 


\section{Figure 4. Schematic Representation of Formalised Informal Accountability Obligations}

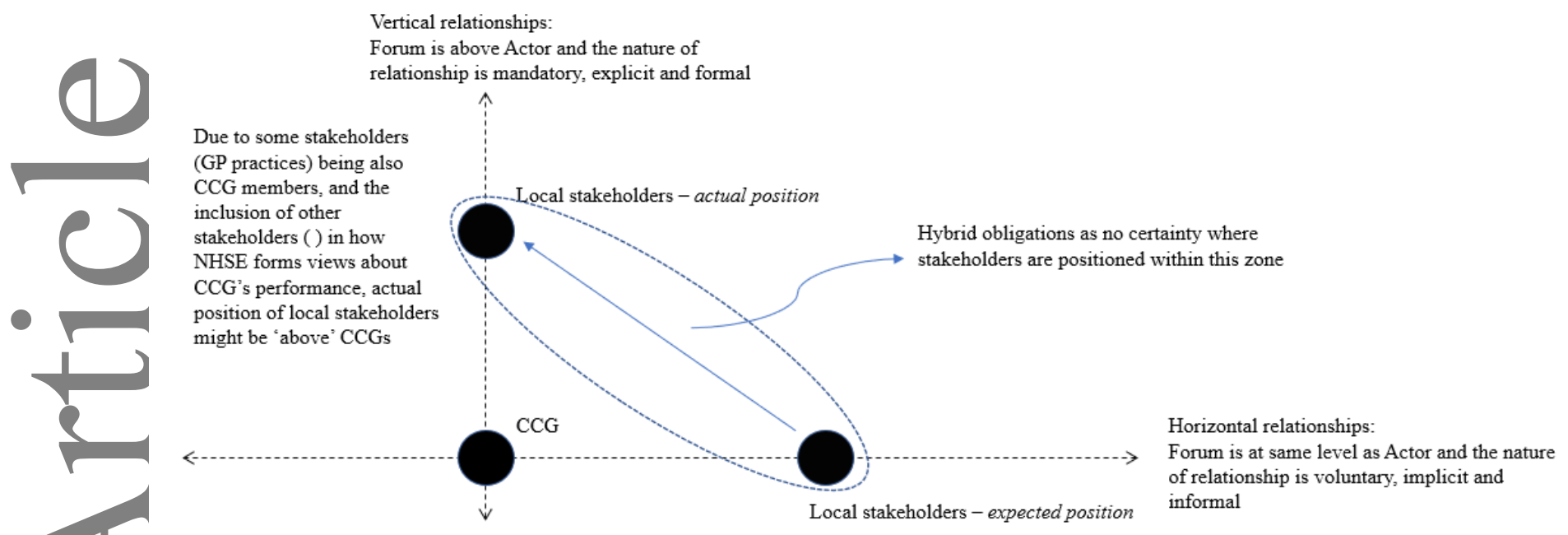

